\title{
Markus Öhler
}

Elia im Neuen Testament

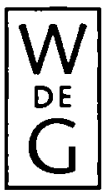




\title{
Beihefte zur Zeitschrift für die neutestamentliche Wissenschaft und die Kunde der älteren Kirche
}

\author{
Herausgegeben von \\ Erich Gräßer
}

Band 88

Walter de Gruyter - Berlin · New York

1997 


\title{
Markus Öhler
}

\section{Elia im Neuen Testament}

\author{
Untersuchungen zur Bedeutung \\ des alttestamentlichen Propheten \\ im frühen Christentum
}

Walter de Gruyter - Berlin · New York 1997 
(@) Gedruckt auf säurefreiem Papier, das die US-ANSI-Norm über Haltbarkeit erfüllt.

Die Deutsche Bibliotbek - CIP-Einheitsaufnahme

[Zeitschrift für die neutestamentliche Wissenschaft und die Kunde der älteren Kirche / Beihefte]

Beihefte zur Zeitschrift für die neutestamentiche Wissenschaft und die Kunde der älteren Kirche. - Berlin ; New York : de Gruyter

Früher Schriftenreihe

Reihe Beihefte zu: Zeitschrift für die neutestamentliche Wissenschaft und die Kunde der äteren Kirche

Bd. 88. Öhler, Markus: Elia im Neuen Testament. - 1997

Ōhler, Markus:

Elia im Neuen Testament : Untersuchungen zur Bedeutung des alttestamentlichen Propheten im frühen Christentum / Markus Öhler.

- Berlin ; New York : de Gruyter, 1997

(Beihefte zur Zeitschrift für die neutestamentliche Wissenschaft und die Kunde der älteren Kirche ; Bd. 88)

Zugl:: Wien, Univ., Diss., 1995

ISBN 3-11-015547-8

ISSN 0171-6441

(C) Copyright 1997 by Walter de Gruyter \& Co., D-10785 Berlin

Dieses Werk einschließlich aller seiner Teile ist urheberrechtlich geschützt. Jede Verwertung außerhalb der engen Grenzen des Urheberrechtsgesetzes ist ohne Zustimmung des Verlages unzulässig und strafbar. Das gilt insbesondere für Vervielfältigungen, Übersetzungen, Mikroverfilmungen und die Einspeicherung und Verarbeitung in elektronischen Systemen

Printed in Germany

Druck: Werner Hildebrand, Berlin

Buchbinderische Verarbeitung. Lüderitz \& Bauer-GmbH, Berlin 
Für Monika 
